International Journal of Instruction e-ISSN: 1308-1470 • www.e-iji.net
July $2018 \bullet$ Vol.11, No.3

p-ISSN: 1694-609X

pp. $163-178$

Received: $22 / 12 / 2017$

Revision: 02/03/2018

Accepted: 07/03/2018

\title{
Factors Affecting In-Service Teachers' Motivation: Its Implication to Quality of Education
}

\section{Gemechu Abera Gobena}

Asst. Prof., Haramaya University, College of Education and Behavioural Sciences, Department of Psychology, Ethiopia, gemechu46@yahoo.com

This study was aimed to assess factors affecting in-service teachers' motivation: its implication to quality of education. Descriptive survey research design was employed in carrying out the study. In-service secondary school teachers from Haramaya University's three colleges were a targeted population. 303 in-service secondary school teachers were sampled from 987 through stratified random sampling. Questionnaires and in service-teachers' portfolio and action research documents were used to get pertinent information for quantitative and qualitative data respectively. Both descriptive and inferential statistics were used to analyse the quantitative data whereas narration was used for qualitative data. The first finding was that $59.70 \%$ of the in-service teachers did not have a reasonable salary. The second finding was that $80.20 \%$ of them were not felt important in the society; the third one was that teachers' level of motivation was contributing $63.20 \%$ to deteriorating quality of education whereas the rest $36.80 \%$ was unexplained variables that have been contributing to deteriorating quality of education.It was recommended that all concerning bodies (ministry of education, zone anddistrict education offices, non-governmental education stakeholders, school principals, supervisors, andparents) in the study areas should search for different mechanisms to improve unreasonable salary,low social factorsand to improve poorly motivated teachers through using different reinforcements techniques in kind and type to sustain the quality- education in the country.

Keywords: department of psychology, Haramaya University, in-service teachers' motivation, quality-education, motivation, eacher

\section{INTRODUCTION}

The issue of teachers' motivation has become a matter of debate and concern in educational systems and standards. In most developing countries of the world including Ethiopia, there has been a growing awareness about teacher motivation which is a key to quality assurance, quality outcomes or delivery and high standards in the education system. It is acknowledged that any nation that is aspiring to maintain high and quality

Citation: Gobena, G. A. (2018). Factors Affecting In-Service Teachers' Motivation: Its Implication to Quality of Education. International Journal of Instruction, 11(3), 163-178. https://doi.org/10.12973/iji.2018.11312a 
standards or achieve quality education in its education system must take teachers and their motivational needs with utmost high level of seriousness (Ofojebe, 2010). There are three things to remember about education. The first one is motivation. The second one is motivation. The third one is motivation (Terrell, 1990 in Adelabu, 2005). Teachers need to know how this conceptual knowledge relates to the classroom and to their instructional role. Moreover, they need to know how to rely on this knowledge when dealing with issues that involve motivational concerns and when making instructional decisions. They are important resources in education. They are also the pivot on which the educational process have been depending upon. They can influence the teaching-learning outcomes either positively or negatively because they determine the quality of instructional delivery and influence quality of education when it comes to the implementation of the curriculum and education policies. "They are to be considered when addressing issues such as quality assurance, quality delivery, quality context and quality learning outcomes" (Onucha, 2002, pp, 27).

In relation to teachers' level of motivation in Ethiopia, VSO (2008) indicated that large number of teachers did not feel motivated due to different factors and they would move to other profession if they have been given alternatives. This study is of a magnificent importance because it is focused on the biggest challenge of every school which is to get the work through their academicians willingly. Motivation of in-service teachers is as important as the blood for sustaining the human life. Teachers who are considered to be the most precious and intellectually sound people who can change the destiny of the nation through contribution of their thought provoking ideas and knowledge is being given the distinguished position in any civilized and non-civilized societies. This research was therefore focused on four important factors, namely reasonable salary, teachers' attitudes, and social factors which directly or indirectly affect teachers' level of motivation in general and quality of education in teaching-learning processes in particular.

\section{THEORETICAL FRAMEWORK}

This part of the paper mainly deals with the theoretical framework of reviewing different literature for the purpose of getting pertinent information from previously conducted research on the area. The review contained salary effect, social factors, teachers' attitudes and teachers' level of motivation. To this end,Akinwunmi (2000) and Ejiogu (1983) found that what the typical low-income earning teacher yearns is a sizeable salary increase, and they conclude that the payment of a living wage would significantly enhance their commitment and performance.The findings of Education For All (EFA) report of 2005 and Bennel (2004) revealed that teachers in developing countries often receive earnings that are insufficient at providing them with a reasonable standard of living and other material benefits were too low for individual and household survival needs to be met. As a result, teachers were highly demotivated to the profession of teachingand leaving schools for better job payment alternatives.

It is widely argued that the status of teachers in most countries, both developed and developing, has declined appreciably during recent decades. Moreover, the forces that are resulting in the 'de-professionalization' of teachers are probably more pronounced in 
low-income generating countries (Ryan \& Deci, 2002). These include protracted economic and social crisis in many of such countries, increasing diversification of the teaching force with increasing reliance on well-educated and qualified teachers with lower job security, generally lower standards of teaching, feminization, poor quality of education and dramatic declines in the standard of living of teachers (Dörnyei, 2001). Work motivation refers to the psychological processes that influence individual behaviour with respect to the attainment of workplace goals and tasks. They received wisdom among occupational psychologists is that "pay on its own does not increase motivation. However, pecuniary motives are likely to be dominant among teachers in those low-income generating countries where pay and other material benefits are too low for individual and household survival needs to be met. Only when these basic needs have been met is it possible for 'higher-order' needs, which are the basis of true job motivation, to be realised (Bennel, etal., 2004).

There is a wide range of views about teacher motivation in Africa, most of which are country specific. However, there appear to be mounting concerns that unacceptably high proportions of teachers working in public school systems in these low-income generating countries that are poorly motivated due to a combination of unreasonable salary, poor incentives, low social factors, low attitudes, and low level of motivation. Consequently, standards of professional conduct and performance are low and resulting in poor quality of education in these countries in general and our country, Ethiopia in particular.

\section{Research aim}

The purpose of this study was to assess the factors affecting in-service teachers' motivation and its implication to quality of education in the study area .Specifically, the study intended to:

(i) Assess the status of in- service secondary school teachers' level of motivations in the study area.

(ii) Identify factors affecting in-service secondary school teachers' level of motivation in teaching-learning processes.

(iii) Pinpoint the extent to which secondary school teachers' motivations affect quality of educations in the study area.

(iv)Investigate the relationship between the teachers' level motivation and social factors.

\section{METHOD}

\section{Research Design}

This study adopted descriptive survey research designs to assess factors affecting inservice teachers' motivation: its implication to quality of education. The researcher was selected this design because it helps him clearly follow the procedures to collect quantitative data in which he used to administers a survey to a sample or to the entire population to describe the attitudes, opinions, behaviours, or characteristics of the population. In this procedure, a survey researcher can collect quantitative and qualitative data using questionnaires and document reviews ( portfolio and action research); he or she statistically analyses the data to describe trends about responses to questions and to 
test research questions or hypotheses (Creswell, 2012). Descriptive survey research designs also used to interpret the meaning of the data by relating results of the statistical test back to past research studies.

\section{Population, Sample Size and Sample Selection Procedure}

The target population for this study consisted of one higher learning institution, Haramaya University, particularly summer in-service public secondary school teachers in College of Natural \& Computational Sciences (CNCS), College of Social Sciences \&Humanities (CSSH), and College of Education \& Behavioural Sciences (CEBS). 303 summer in-service secondary school teachers were taken from 987 as a targeted population. The in-service teachers were selected because they are directly concerned with the quality of education and they know the extent to which they have been motivated by the employer or the government. The colleges were selected through purposive sampling techniques while303 in-service teachers were selected throughstratified random sampling. This was used because the study intended to select a representative without bias from the accessible population. This ensured that each member of the target population had an equal and independent chance of being included in the sample.Stratified random sampling technique was used because firstly, there were different subdivisions in the targeted population which are important to be considered. Secondly, there were also variations in population sizes of different strata in this case sex, experience, department and colleges.

\section{Instrumentation-Questionnaire and document review}

A three section questionnaire was used to collect relevant data. Section-I was consisted of information on socio-demographic data; section-II was consisted of items focusing on teachers' level of motivation and section-III was consisted of items focusing on quality of education. A pilot study was conducted on sixteen in-service teachers (eight females and eight males) who represented the population character but not the sample to check the reliability of the items by using Crookback Alpha. Accordingly, the researcher was able to decide the characteristics of the questionnaire that needed to be adjusted or remained or to be changed in some technical words or phrases that seemed to be technical for these respondents. The reliability of the questionnaire was, therefore calculated as 0.89 and 0.91 for the second and third sections of the questionnaire which was found to be highly reliable, respectively. Therefore, it was safe to use them with a little modification. The validity was tested by expert and well experienced teachers over the area. The questionnaire was administered on face to face basis so that the distributed questionnaires were collected from the in-service secondary school teachers after they were completing filling their responses. Some sample portfolio and action research documents of these in-serviced teachers were reviewed qualitatively to support or to substantiate the quantitative findings.

\section{Method of Data Analysis}

For proper understanding and evaluation of the purpose of the research questions raised and to ultimately achieve the research objectives, different techniques of analyses were employed. Mainly, the techniques of analysis used were bivariate level of analysis. The 
descriptive statistics such as frequency, percentages, means, and standard deviationwere used to summarize socio-demographic variables of the respondents and respondents' response to theteachers' level of motivation while inferential statistics, like bivariate correlation, independent chi-square test, stepwise multiple regressionandone way Analysis of Variance (ANOVA) were used to show the degree of strength or relationship, associations among the variables, average relationship to predict or estimate the most likely value of those variables and the mean differences among groups respectively in the second and third section of the questionnaire. The level of significance was set to $\alpha=0.05$.

\section{FINDINGS AND DISCUSSIONS}

This chapter has two parts: the first part deals with the characteristics of the respondents; and the second part presents the analysis and interpretation of the main findings. To this end, both quantitative and qualitative data were gathered through questionnaire and document reviews. The data gathered through document reviews were supposed to supplement the quantitative data. Questionnaire was distributed to 315 inservice teachers from three colleges and 303 (96.20\%) copies were returned. The respective quantitative data were analysed quantitatively using frequency, percentage, mean, standard deviation, chi-square tests, one way ANOVA and stepwise multiple regression. On the other hand, the triangulations were made to check the consistencies and variations of the result obtained from both instruments. The analysed data were compiled and organized in a way that it suits the interpretations of the results in addressing the research questions. In this way, 6tables were constructed in categorizing the objectives of the study in thematic groups in details to deal with the responses of the participants. The quantitative data obtained from respondents were analysed using the Statistical Package for the Social Sciences (SPSS version 16).

\section{Respondents Characteristics}

Under this section, respondents' socio-demographic characteristics by sex and college are going to be discussed in details

Table1

Respondents' demographic characteristics by sex

\begin{tabular}{lcl}
\hline Sex & Frequency & Percent \\
\hline Male & 233 & 76.90 \\
Female & 70 & 23.10 \\
\hline Total & 303 & 100.0 \\
\hline
\end{tabular}

As the table1 shows, the majorities $(233,76.90 \%)$ of the total sampled summer inservice secondary school teachers were males whereas $(70,23.10 \%)$ of them were females. From this, it canbe suggested that there was a big gap of sex difference among in-service secondary school teachers in the selected samples. 
Table2

Respondents' characteristics by college

\begin{tabular}{lll}
\hline Colleges & Frequency & Percent \\
\hline College of Natural and Computational Sciences (CNCS) & 168 & 55.40 \\
College of Social Sciences and Humanities (CSSH) & 74 & 24.40 \\
College of Education and Behavioural Sciences (CEBS) & 61 & 20.20 \\
\hline Total & 301 & 100.0 \\
\hline
\end{tabular}

From the table2, it can be understood that the majorities $(168,55.40 \%)$ of the respondents were selected from CNCS; $(74,24.40 \%)$ of them were from CSSH and the rest $(61,20.20 \%)$ of them were from CEBS. This seemed that the 55.40: 44.60 enrolment ratios were seemed to be implemented as per the national curriculum of the country which was natural sciences to social sciences ratio was70: 30, respectively.

\section{Factors Affecting In-Service Teachers' Motivation}

The following parts of the analyses were mainly dealt with factors contributing to demotivating in-service secondary school teachers. These factors include reasonable salary, social factors, teachers' attitudes and quality of education. Therefore, the researcher tried to organize, present, analyse and interpret both quantitative and qualitative data that he collected through questionnaire and sample portfolio and action research documents done by these participants were reviewed respectively as follows.

Table 3

Salary effect on teachers' level of motivation $\left(\mathrm{n}_{\mathrm{i}}=303, \mathrm{p}<0.05\right)$

\begin{tabular}{|c|c|c|c|c|c|c|c|c|}
\hline \multirow{2}{*}{\multicolumn{2}{|c|}{ No Items }} & \multicolumn{4}{|c|}{ Descriptive Analysis } & \multicolumn{3}{|c|}{ Inferential Analysis } \\
\hline & & No & $\%$ & Yes & $\%$ & df & $\chi^{2}$ & Sig. \\
\hline 1 & Do you have a reason-able salary? & 181 & 59.70 & 122 & 40.30 & 1 & 11.49 & 0.01 \\
\hline 2 & Do you receive your salary on time? & 106 & 35.00 & 197 & 65.00 & & & \\
\hline & & & & & & 1 & 27.33 & 0.00 \\
\hline 3 & $\begin{array}{l}\text { Is there any other earning hand in } \\
\text { your family? }\end{array}$ & 203 & 67.00 & 100 & 33.00 & 1 & 35.01 & 0.00 \\
\hline 4 & Do you live in a joint family system? & 137 & 45.20 & 166 & 54.80 & 1 & 2.78 & 0.09 \\
\hline 5 & $\begin{array}{l}\text { Is your income sufficient to meet } \\
\text { your basic financial requirements? }\end{array}$ & 257 & 84.80 & 46 & 15.20 & 1 & 146.9 & 0.00 \\
\hline 6 & $\begin{array}{l}\text { Are you satisfied with the economic } \\
\text { level of your family? }\end{array}$ & 269 & 88.80 & 46 & 11.20 & 1 & 182.3 & 0.00 \\
\hline 7 & Do you have all necessities of life? & 252 & 83.20 & 51 & 16.80 & 1 & 133.3 & 0.00 \\
\hline 8 & $\begin{array}{l}\text { Do you aspire that your present } \\
\text { economic status should improve? }\end{array}$ & 131 & 43.20 & 172 & 56.80 & 1 & 5.50 & 0.02 \\
\hline 9 & $\begin{array}{l}\text { Do you think that you receive less } \\
\text { salary as compared to the work you } \\
\text { do? }\end{array}$ & 93 & 30.70 & 210 & 69.30 & 1 & 45.19 & 0.00 \\
\hline 10 & $\begin{array}{l}\text { Does the low income affect your } \\
\text { teaching work? }\end{array}$ & 68 & 22.40 & 235 & 77.60 & 1 & 92.04 & 0.00 \\
\hline
\end{tabular}

As it can be observed from the table3, item1, the majorities $(181,59.70 \%)$ of the respondents did not have a reasonable salary for their teaching profession whereas the rest $(122,40.30 \%)$ of them had a reasonable salary in their teaching profession. Furthermore, from item by item analysis of chi-square test, it was concluded that there 
was statistically a significant associations among teachers' salary pay and teachers' level of motivation, $\chi^{2}(1, \mathrm{n}=303)=11.90, \mathrm{p}<0.05$, one tailed. In the same way, item 2 of table3, the majorities $(197,65.00 \%)$ of the respondents received their basic salary on time whereas $(106,35.00 \%)$ of them did not receive their basic salary on time. This indicates that teachers who did not receive their basic salary on time developed a negative attitude towards teaching professions. Moreover, an item by item analysis of chi-square test was shown that there was statistically a significant association among teachers who did not receive their salary on time and teachers' level of motivation, $\chi^{2}$ $(1, \mathrm{n}=303)=27.33, \mathrm{p}<0.05$, one tailed.

In the same way, it was indicated in table 3 item 3, the majority $(203,67.00 \%)$ of the respondents did not have any other earnings except their basic salary from teaching professions, but $(100,33.00 \%)$ of them had other sources of earnings outside of teaching profession. Due to this problem, most teachers had economic problems in providing basic needs for their families. Furthermore, an item by an item analysis of chi-square test showed that there was a statistically significant association between teachers who did not get other sources of earnings and their level of motivation, $\chi^{2}(1, \mathrm{n}=303)=35.01$, $\mathrm{p}$ $<0.05$, one tailed. In the same table 3 item 4 , it was indicated that the majorities $(166$, $54.80 \%)$ of the respondents were living with joint family system whereas $(137,45.20 \%)$ of them were not living with any joint family system. Moreover, an item by an item analysis of chi-square test concluded that there was no statistically a significant association among teachers who live with the joint family systems and their level of motivation, $\chi^{2}(1, \mathrm{n}=303)=2.78, \mathrm{p}>0.05$, one tailed.

As it has been shown in table3 item5, the majorities $(257,84.80 \%)$ of the participants indicated that their monthly income was not enough for basic needs and related expenses; however, $(46,15.20 \%)$ of them identified that their monthly income was enough for basic needs and other related expenses. Furthermore, from chi-square test, it was shown that there was statistically a significant association between teachers' monthly income and their level of motivation, $\chi^{2}(1, \mathrm{n}=303)=146.93, \mathrm{p}<0.05$, one tailed. From the same table 3 of item 6, it was identified that the majorities (269, $88.80 \%)$ of the participants were not satisfied with the economic level of their families, but $(34,11.20 \%)$ of them were satisfied with their present economic level of their families. From chi-square test, one can conclude that there was a statistically significant association between in-teachers who were not satisfied with their economic level and their level of motivation, $\chi^{2}(1, \mathrm{n}=303)=182.3, \mathrm{p}<0.05$, one tailed. Even though respondents' response was not consistent on their perceptions about their teaching profession, it can be implied that teachers were not enthusiastic in their profession due to their economic level and lack of other sources of additional income to compensate expense costs of their life. This was not supported by portfolio and action research documents reviews at woreda and school levels.

From the data given in the table 3 item7, the majorities $(252,83.20 \%)$ of the participants did not have all necessities of life in their home, but $(51,16.80 \%)$ of them had enough necessities in all their life. Besides, chi-square test analysis shown that there was statistically a significant association between teachers who did not have all necessities in 
their life and their level of motivation, $\chi^{2}(1, \mathrm{n}=303)=133.34, \mathrm{p}<0.05$, one tailed. From the same table 3 item8, it can easily be identified that the majorities $(172,56.80 \%)$ of the respondents were aspired to their present economic status so as to improve their way of living, nevertheless $(131,43.20 \%)$ of them were not aspired to their present economic status to be improved. Moreover, the chi-square test analysis was concluded that there was statistically a significant association between teachers who were aspired to present economic status and teachers' level of motivation, $\chi^{2}(1, \mathrm{n}=303)=5.5, \mathrm{p}<$ 0.05 , one tailed. This was not supported by sampled portfolio and action research document reviews.

From table 3 item9, it was pinpointed that the majorities $(210,69.30 \%)$ of the respondents were received less salary as compared to other professions, but (131, $30.70 \%$ ) of them were received enough salary as compared to other profession. Moreover, from chi-square test, it was concluded that there was statistically a significant association between teachers who were receiving less salary as compared to other work and their level of motivation, $\chi^{2}(1, \mathrm{n}=303)=45.19, \mathrm{p}<0.05$, one tailed. This was not supported by sampled portfolio and action research document reviews. Finally, as table 3 item 10 was pinpointed that the majorities $(235,77.60 \%)$ of the respondents were highly affected by low income generating sources, but only $(68,22.40 \%)$ of them were not affected by low income. Furthermore, the chi-square test analysis was concluded that there was statistically a significant association between teachers who have been affected by low income and their level of motivation, $\chi^{2}(1, \mathrm{n}=303)=92.04, \mathrm{p}<0.05$, one tailed. This was highly supported by sampled portfolio and action research document reviews.

To support presented analyses, Degefew (2012) stated that in many developing countries teaching has historically enjoyed a large degree of prestige. Today, however, many teachers feel the respect for their profession is decreasing-in the eyes of students, parents, government and the broader society. Low salaries play a role, but so does the assignment of administrative or menial tasks; lower standards of teaching; increasing demands on schools from communities; and the creation of large groups of unqualified female teachers (Bennell and Akyeampong, 2007). In addition, sometimes teachers may simply not have a good relationship with the community around the school, and this can be especially true in hierarchical societies with large gaps between teachers, the students and community.

Table4

Social factors of teachers' motivation $\left(n_{i}=303, p<0.05\right)$

\begin{tabular}{llllllllr}
\hline No & Items & \multicolumn{3}{c}{ Descriptive Analysis } & \multicolumn{3}{c}{ Inferential Analysis } \\
\cline { 3 - 9 } & & No & $\%$ & Yes & $\%$ & df & $\chi^{2}$ & Sig. \\
\hline 1. & $\begin{array}{l}\text { Do you feel that you are given } \\
\text { importance in the society? }\end{array}$ & 60 & 19.80 & 243 & 80.20 & 1 & 110.53 & 0.00 \\
\hline 2. & $\begin{array}{l}\text { Are you ready to face all kinds of } \\
\text { problems in class? }\end{array}$ & 45 & 11.90 & 258 & 85.10 & 1 & 149.33 & 0.00 \\
\hline 3. & $\begin{array}{l}\text { Do you think that you have a lot of } \\
\text { social abilities? }\end{array}$ & 59 & 19.50 & 244 & 80.5 & 1 & 224.82 & 0.00 \\
\hline 4. & Does your family depend on you? & 147 & 48.5 & 156 & 51.50 & 1 & 0.27 & 0.61 \\
\hline 5. & Do you feel yourself better than others? & 164 & 54.10 & 139 & 44.90 & 1 & 2.06 & 0.15 \\
\hline
\end{tabular}




\begin{tabular}{lllllllll}
\hline 6 & Do you like yourself? & 53 & 17.50 & 250 & 82.50 & 1 & 128.01 & 0.00 \\
\hline 7 & Do you hesitate to meet other people? & 134 & 44.20 & 169 & 55.80 & 1 & 4.04 & 0.04 \\
\hline 8 & $\begin{array}{l}\text { Are you satisfied with your present } \\
\text { perform-ance? }\end{array}$ & 110 & 36.30 & 193 & 63.70 & 1 & 22.74 & 0.00 \\
\hline $\begin{array}{l}\text { Do you think that you are a good } \\
\text { person? }\end{array}$ & 27 & 8.90 & 276 & 91.10 & 1 & 22.74 & 0.00 \\
\hline 10 & Do people love you? & 21 & 6.90 & 282 & 93.10 & 1 & 204.62 & 0.00 \\
\hline 11 & $\begin{array}{l}\text { A re you affected with any physical } \\
\text { disease? }\end{array}$ & 275 & 90.80 & 28 & 9.20 & & 224.82 & 0.00 \\
\hline 12 & Does your disease affect your teaching? & 282 & 93.10 & 21 & 6.90 & 1 & 201.35 & 0.00 \\
\hline 13 & Have you self-confidence? & 11 & 3.60 & 292 & 96.40 & 1 & 260.60 & 0.00 \\
\hline
\end{tabular}

As it can be understood from table4 item1, the majorities $(243,80.20 \%)$ of the respondents did not feel important in the society, but only $(60,19.80 \%)$ of them were felt important in the society. Furthermore, from chi-square test, it was concluded that there was statistically a significant association between teachers who did not feel important by the society and their level of motivation, $\chi^{2}(1, \mathrm{n}=303)=110.53, \mathrm{p}<0.05$, one tailed. This idea was not well supported by the sampled portfolio and action research document reviews. In the same way, table4, item 2 was pinpointed that the majorities $(258,85.10 \%)$ of the respondents were ready to face any kinds of problems in classroom, but only $(45,11.90 \%)$ of them were not ready to face any kind of situations in the classroom. Besides, chi-square test was shown that there was statistically a significant association between teachers who were ready to face any kind of the problems in classroom and teachers' level of motivation, $\chi^{2}(1, n=303)=149.73$, $p<$ 0.05 , one tailed. This idea was fully supported by sampled portfolio and action research document reviews.

As it can be understood from the same table item3, the majorities $(244,80.50 \%)$ of the participants had enough social abilities towards their profession; however, $(59,19.50 \%)$ of them did not have enough social abilities towards their profession. In addition, the chi-square test analysis was shown that there was statistically a significant association between teachers social ability and their level of motivation, $\chi^{2}(1, n=303)=224.82$, $p$ $<0.05$, one tailed. This idea was fully supported by sampled portfolio and action research document reviews of the sampled respondents. As it can be seen from table 4 item4, the majorities $(156,51.50 \%)$ of the respondents had families who have been depending on them for basic needs, but $(147,48.50 \%)$ of them did not have families who have been depending on them for basic needs. Besides, the chi-square test analysis was pinpointed that there was no statistically a significant association between teachers whose families have been depending on them for basic needs and teachers' level of motivation, $\chi^{2}(1, \mathrm{n}=303)=0.27, \mathrm{p}>0.05$, one tailed. This idea was partially supported by sampled portfolio and action research document reviews.

As it can be understood from the table4 item5, the majorities $(164,54.10 \%)$ of the respondents did not feel better than others, but $(139,45.90 \%)$ of them felt better than others. From thechi-square test, it was pinpointed that there was no statistically significant association between in-service teachers who felt better and their level motivation $\chi^{2}(1, \mathrm{n}=303)=2.06, \mathrm{p}>0.05$, one tailed. However, the sampled portfolio and action research document reviews did not show us that they were felt better than 
others. This indicates that most teachers lacked confidence in their professions. From the same table4 item6, the majorities $(250,82.50 \%)$ of the respondents did not feel better than others; however, $(53,17.50 \%)$ of them were felt better than others. Besides this finding, the chi-square test analysis was indicated that there was statistically a significant association between teachers feeling about themselves and their level of motivation, $\chi^{2}(1, \mathrm{n}=303)=228.01, \mathrm{p}<0.05$, one tailed.

As it can be seen from the same tableitem7, the majorities $(169,55.80 \%)$ of the respondents were hesitated to meet other people who are out of teaching professions ,but $(134,44.20 \%)$ of them were not hesitated meeting other people who were outside of teaching profession. This indicates that most teachers lacked confidence in their professions. From the chi-square test analysis, it was identified that there was statistically significant association between teachers feeling and their level of motivation, $\chi^{2}(1, \mathrm{n}=303)=4.04, \mathrm{p}<0.05$, one tailed. However, the sampled portfolio and action research document reviews did not show us that the respondents were not as such weak confidence in their preferences. As table4 item8 reveals, the majorities (193, $63.70 \%$ ) of the respondents were not satisfied with their present performance, nevertheless $(110,36.30 \%)$ of them were satisfied with their present performance. In addition, the chi-square test analysis shown that there was statistically a significant associations between teachers present teaching performance satisfactions and their level of motivation, $\chi^{2}(1, n=303)=22.74, p<0.05$, one tailed. However, the sampled portfolio and action research work of the respondents' document reviews were shown us that teachers were not satisfied with their present performance. From the same table4 item9, the majorities $(276,91.10 \%)$ of the respondents were perceived themselves as a good person, but only $(27,8.90 \%)$ of them were not perceived themselves as a good person. From item by item analysis of chi-square test, it was concluded that there was statistically a significant association between teachers who perceived themselves as a good person and their level of motivation, $\chi^{2}(1, n=303)=22.74, p<0.05$, one tailed. However, these sampled portfolio and action research work of the respondents' document reviews were shown us that teachers were satisfied themselves as a good person.

As it can be understood from the same table item10 given, the majorities $(282,93.10 \%)$ of the respondents were liked by other people, but only $(21,6.90 \%)$ of them were not liked by other peoples. From chi-square test, it was identified that there was statistically a significant association between teachers who were liked by other people and their level of motivation, $\chi^{2}(1, \mathrm{n}=303)=224.82, \mathrm{p}<0.05$, one tailed. However, the sampled portfolio and action research work done by the respondents' document reviewswere shown us that teachers were very much liked by other peoples particularly by parents. From the same table item11, the majorities $(282,93.10 \%)$ of the respondents were not affected with any other physical diseases, but only $(21,6.90 \%)$ of them were affected physical diseases. From chi-square test, it was pinpointed that there was statistically a significant association between teachers who were not affected by any physical diseases and their level of motivation, $\chi^{2}(1, \mathrm{n}=303)=201.35, \mathrm{p}<0.05$, one tailed. However, the sampled portfolio and action research work done by the respondents' document reviews were showed us that teachers were not affected by any physical diseases. 
As it can be seen from the same table 4 item12, the majorities $(292,96.40 \%)$ of the respondents responded that they were not affected by any physical problems, but only $(20,8.5 \%)$ of them were affected by physical problems. Furthermore, the chi-square test was identified that there was statistically significant associations between teachers who were not affected by physical problems and their level of motivation, $\chi^{2}(1, n=303)=$ $260.60, \mathrm{p}<0.05$, one tailed. However, the sampled portfolio and action research work done by the respondents' document reviews were shown us that teachers were not affected by any physical problems. As it can be understood from the same table, item13, the majorities $(292,96.40 \%)$ of the respondents had enough self confidence, but only $(11,3.60 \%)$ of them did not have enough self confidence. Moreover, the chi-square test was pinpointed that there was statistically a significant associations between teachers who have had enough self confidence and their profession, $\chi^{2}(1, n=303)=260.60, p<$ 0.05 , one tailed. However, the sampled portfolio and action research work done by the respondents' document reviews were shown us that teachers were enough self confidence about their profession

In support of these findings, Hartmann (2008;Popa and Acedo (2006) found that"lack of prestige from low remuneration and low autonomy in planning and teaching has been associated with private tutoring in Romania and Egypt -an activity where teachers often enjoy more professional status, self-esteem, and better pay. Many teachers feel that another way to increase societal respect for teaching is to improve the public image of their profession by making the public more aware of the actual conditions that teachers face. A review of empirical studies on teacher motivation in developing countries by Bennell and Akyeampong (2007)indicates widespread low or decreasing levels of motivation were resulting in lower quality of education. Besides, it was found that sizeable percentages of secondary school teachers are poorly motivated in Sub-Saharan Africa and South Asia. The issue of quality in level of education in sub-Saharan Africa is inseparable from the quality of the teachers involved.

Table5

Descriptive and inferential statistical analysis on teachers' level of motivation versus quality of education $\left(\mathrm{n}_{\mathrm{i}}=303, \mathrm{p}<0.05\right)$

\begin{tabular}{|c|c|c|c|c|c|c|c|c|}
\hline \multicolumn{3}{|l|}{ Descriptive Analysis } & \multicolumn{6}{|c|}{ Summary of ANOVA Table ( Inferential Analysis) } \\
\hline Variables & Mean & SD & SV & SS & df & MS & $\mathrm{F}$ & Sig. \\
\hline \multirow{3}{*}{$\begin{array}{l}\text { Teachers' Level of } \\
\text { motivation }\end{array}$} & \multirow[t]{3}{*}{2.31} & \multirow[t]{3}{*}{1.36} & Between Groups & 14.034 & 1 & 14.03 & 7.73 & 0.006 \\
\hline & & & Within Groups & 546.42 & 301 & 1.82 & & \\
\hline & & & Total & 560.46 & 302 & & & \\
\hline
\end{tabular}

As it can be understood from table5, the computed mean score $(\mathrm{M}=2.31)$ of the respondents indicated that their level of motivation towards teaching profession was low. Moreover, the computed standard deviation $(\mathrm{SD}=1.36)$ from the same table indicated that there was little variation among respondents in their level of motivation. Furthermore, the computed F ratio at $\alpha=0.05, \mathrm{~F}(1,301)$ was found to be 7.73 which was greater than the critical region at $\alpha 0.05, \mathrm{~F}(1,301)$ is 3.94 . Therefore, it can be concluded that there was statistically significant mean difference among respondents in 
their level of motivation. This indicated that in any educations systems student-learning suffers due to difficulties attracting high-quality teachers, low motivation for teachers to perform their jobs well, and teacher attitudes. As a result, the quality of education was extremely affected by low teachers' level of motivation. Education planners should therefore carefully consider the impact of their decisions on teachers and their motivations to teach.

Table6

Régressionanalysis $\left(\mathrm{n}_{\mathrm{i}}=303, \mathrm{p}<0.05\right)$

\begin{tabular}{|c|c|c|c|c|c|c|c|}
\hline \multicolumn{8}{|c|}{ Coefficients } \\
\hline \multirow[b]{2}{*}{ Model } & \multirow[b]{2}{*}{$\mathrm{R}$} & \multirow[b]{2}{*}{$\mathrm{R}^{2}$} & \multicolumn{2}{|c|}{ USC } & \multicolumn{2}{|l|}{$\mathrm{SC}$} & \multirow[b]{2}{*}{ Sig. } \\
\hline & & & B & SE & Beta & $\mathrm{t}$ & \\
\hline (Constant) & & & 3.497 & 0.295 & & 11.854 & 0.000 \\
\hline \multirow{2}{*}{$\begin{array}{l}2 \frac{\text { Teachers' Attitudes }}{\text { Teachers' Level of }} \\
\text { Motivation }\end{array}$} & \multirow[t]{2}{*}{0.795} & \multirow[t]{2}{*}{0.6320} & -0.733 & 0.062 & -0.210 & -3.747 & 0.000 \\
\hline & & & -0.603 & 0.041 & -0.141 & -2.518 & 0.012 \\
\hline
\end{tabular}

As the table 6 reveals, the regression analysis on the extent to which teachers' level of motivations affect quality education were teachers' attitudes and teacher' level of motivation. From the egression correlation coefficient $(\mathrm{R}=0.795)$ analysis, teachers' attitudes and their level of motivation were contributing $((\mathrm{R} 2) * 100 \%)=63.20 \%$ to deteriorating quality of education; however, unexplained variables was contributing (1$\mathrm{R}^{2}$ )*100 $=36.80 \%$ to deteriorating quality of education. The $\mathrm{t}$-value is significant for the two variables, namely teachers' attitudes and their level of motivation.

The SPSS computer printout shows a multiple regression equation that predicts the extent to which teachers' attitudes $\left(\mathrm{x}_{1}\right)$ and their level of motivations $\left(\mathrm{x}_{2}\right)$ affect quality of education were statistically significant independent variables. Therefore, the multiple regression equation for dependent variable- quality of education $(\mathbf{Y})$ could be expressed in terms of these statistically significant independent variables that have already been

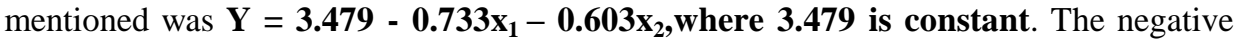
slopes of the two variables respectively were $(-0.733$ and -0.603$)$ which used to show us that per a unit increase of the independent variables would tend to respectively decreases $(-0.733$ and -0.603$)$ dependent variable that is the quality of education.

\section{CONCLUSION}

Based on the results and discussions parts, the researcher drew the following conclusions:

$\checkmark$ As far as the status of in-service teachers' level of motivation was concerned, it was concluded that the majorities of the teachers were either poorly or very poorly motivatedto the profession of teaching. 


\section{Lack of reasonable salary}

As it was indicated in discussion and result part, it was concluded that the majorities of the sampled in-service teachers did not have a reasonable salary from their teaching profession. As a result of low salary, teachers were searching other sources of income generating activities which in turn affecting teachers' time utilization and optimum use of their effort in supporting their students. Moreover, the majorities of the inservice teachers did not have any other income generating activities except basic salary even though they were searching additional income generating activities. Due to this problem, most of the in-service teachers had economic problems in providing basic needs for their families. Since most of them wereliving with their joint families, the income earning from the teaching profession were not adequate enough to support these families.

$\checkmark \quad$ Therefore, living with such systems directly or indirectly affects teachers' living standard and cost. Moreover,the majorities of the in-service teachers did not have all necessities and facilities of life in their home as a result of insufficient basic salaries and lack of extra income generating activities. Teachers in both rural and urban areas were highly demotivated to teaching professions. As a result of these issues, most of them were aspired to their present economic status so as to get improved salary payment. Therefore, the low salary payment for in-service teachers influence the overall prestige and attractiveness of the profession and teachers often say that increased pay would improve their morale of staying actively in teaching profession.

\section{Social factors affecting teachers' motivation}

$\checkmark$ It was found that the second factors affecting teachers' motivation in teachinglearning processes were identified as social factors. From the discussion and result part, it was found that the majorities of the in-service teachers were not felt important in the society. This is quite enough evidence to support the claim that teachers did not feel important by the society. From this finding, it was concluded that most teachers lacked confidence on their professions. The other social factors affecting teachers' motivation was hesitating to meet other people outside of teaching profession. As a result of this the majorities of them were hesitated to meet other people who were outside of teaching professions. Due to the above stated reasons, most of them were not satisfied with their present performance. From the discussion part, it was identified that most of the in-service teachers were not affected with any other physical problems. This is a mechanism by which teachers' motivation has been promoted. Finally, it was concluded that there were statistically a significant weak negative relationship between teachers' level of motivation and economic status variables (lack of reasonable salary, lack of other income generating, living in a joint family, insufficient income to meet basic financial requirement, lack of satisfaction with the economic level of the family, lack of having all the necessities of life, lack of improving the aspiration of present economic status, and low income effect on teaching profession).

The extent to which teachers' level motivations affect quality- educations in the study area 
From the computed mean score of the respondents, it was shown that teachers' level of motivation towards teaching profession was low. However, from one way ANOVA analysis, it was concluded that there were statistically significant mean difference among respondents in their' level of motivation. This indicated that in any educations systems student-learning suffers due to difficulties in attracting high-quality teachers, low level of teachers' motivation and teachers' attitude towards teaching profession. As a result, the quality of education was extremely affected by low teachers' attitude and their low level of motivation.

$\checkmark$ From the discussions and results section, it was concluded that teachers' attitudes and their level of motivation were contributing $63.20 \%$ to deteriorating quality of education; however, $36.80 \%$ were contributing to deteriorating quality of education by unexplained variables.

\section{RECOMMENDATIONS}

On the bases of the conclusions drawn from the data presented above, the researcher would like to forward the following recommendations.

$\checkmark$ To direct the teaching learning process in a better way, the school practices on teachers' level of motivation should be improved. Therefore, in order to sustain the quality of education to better use teachers' knowledge and skills and to improve student achievement, the following recommendations were forwarded to all concerning bodies (ministry of education, non-governmental education stakeholders, school principals, supervisors, zonal education offices, woreda (district) education offices, parents, and teachers) in the study areas.

$\checkmark$ Salary does not cover basic household survival needs of teachers, let alone enable them to enjoy a reasonable standard of living. Indeed, careful analyses of the literature seem to suggest that salary is crucial in teachers' level of motivation among the developing countries. Therefore, the Ethiopian education stakeholders should provide bonuses to improve teachers' performance through providing monetary rewards as it is the strongest incentive for teachers' level of motivation in Ethiopia, especially salary increases on performance based awards. Generally, teachers must have the supporting pillars in adequate pay, recognition, accountability, career development, institutional environment, voices to any request, and materials.

$\checkmark$ Low social factors such as (lack of social competencies, lack of confidence about their professions, lack of respect from the classroom, hesitation to meet other people outside of teaching profession and lack of satisfaction in their performance) were the social factors that demotivated teachers' level of motivation. Thus, the in-service teachers must have a status which corresponds to their key role in the advancement of education and to the importance of their contribution to the development of the individual and a society as a whole. Hence, the social factors of the teaching profession in the broader community are an important factor in teachers' attitudes and their level of motivation. So, the status of teachers must have a direct bearing on the quality of education and many of the skills of the teacher can be ascribed to the different manner in which the society has looked up on the teachers' attitudes and their level of motivation (Martin, 2007). 
Access to quality of education for Ethiopian high schools of going age in Ethiopia is a constitutional provision. Apart from gaining access, teachers are the most important factor in determining quality of education that Ethiopian students receive. For this reason, the government of Ethiopia and other stakeholders in education has a responsibility to ensure that teachers ought to be well motivated to deliver their best in terms of imparting knowledge to Ethiopian high school students.

\section{IMPLICATIONS}

In implication, teachers' level of motivation, teachers' attitude, and social factors have a high detrimental effect to individual and society, which can lead to negative outcomes including low academic outcomes among learners, increased students' failure and drop out, attrition problems, impaired ability to work effectively, and also existing problems of initiation for further achievement. Therefore, meeting teachers' physiological needs, social needs, economic needs and moral needs is the responsibility of governments, parents and the whole societies for the betterment of the next generations of the country in general and the globe in particular. Government should provide teachers with enough salary, house, educational facilities and carer development and transport facilities before teachers are going to blame the system as a whole.

\section{REFERENCES}

Adelabum M.A.(2005). Teacher motivation and incentives in Nigeria. Its meaning and measure. Review of Educational Research, 68, 202-248.

Alam,T.A \& Farid,S.. (2011). Factors affecting teachers motivation: International Journal of Business and Social Science Vol. 2 No. 1; January 2011.

Akinwumi, F.S. (2000). Impact of motivation and supervision on teacher productivity in secondary schools in Oyo State Nigeria. An Unpublished Ph.D. thesis submitted to the Faculty of Education, University of Ibadan Nigeria.

Baron, R. A. (1991). The physical environment of work settings: Effects on task performance, interpersonal relations, and job satisfaction. Research in Organizational Behavior, 16, 1-46.

Bennell, P. (2004).Is There a Teacher Motivation Crisis in Tanzania?Brighton: Knowledge and Skills for Development.

Bennell, P. and Akyeampong, K. (2007).Teacher motivation in Sub-Saharan Africa and South Asia. Education Paper prepared for DFID, Brighton: Knowledge and Skills for Development.

Bennell, P.S., Harding,J. and Rogers-Wright,S..(2004). PRSP Education sector review in Sierra Leone. Ministry of Education, Science and Technology, Freetown.

Deci, E. L., Koestner, R., \& Ryan, R. M. (1999). A meta-analytic review of experiments examining the effects of extrinsic rewards on intrinsic motivation. Psychological Bulletin, 125(6), 627-668. 
Ejiogu, A. (1983). School Personnel Management: A Nigerian perspective, Lagos University.

Press. Elliot, A. J. (2005). A conceptual history of the achievement goal constructs. Handbook of competence and motivation (pp. 52-72). New York: Guilford Publications.

Gedefaw, K. (2012). Job satisfaction of secondary school teachers in Ethiopia. University of South Africa (PhD, Dissertation).

Gibson, S., \& Dembo, M. (1984). Teacher efficacy: A construct validation. Journal of Educational Psycology, 76 (4),569-582.

Hartmann, S. (2008). The Informal Market of Education in Egypt: Private Tutoring and its Implications. Working Papers, Institut für Ethnologie und Afrikastudien, 2008.

Kanfer, R., Chen, G., \& Pritchard, R. D. (2008). Work motivation: Forging new perspectives directions in the post-millennium. Work motivation: Past, present, and future (pp. 601-631). New York: Taylor \& Francis.

Martin, A. J. (2007). Examining a multidimensional model of student motivation and engagement using a construct validation approach. British Journal of Educational Psychology, 77, 413-440. doi:10.1348/ 000709906X118036.

Ofojebe, W.N. (2010). Teachers' motivation and its influence on quality

assurance in the Nigerian educational system. African Research Review,4(2). doi:10.4314/afrrev.v4i2.58352.

Onocha, C.O. (2002). Quality assurance in teacher education. Teacher education in Nigeria: past, present and future proceedings of the first Teachers' summit, February 2002. Kaduna: National Teachers' Institute.

Ryan, R. M. and Deci, E. L. (2000). Intrinsic and extrinsic motivations: Classic definition and new directions. Contemporary Educational Psychology, 25:54-67.

Schwarzer, R. (1992). Self-efficacy: Thought control of action. Washington, DC: Hemisphere.

Steers, R. M., Mowday, R. T., \& Shapiro, D. L. (2004). The future of work motivation theory. Academy of Management Review, 29, 379-387.

Voluntary Services Overseas [VSO]. (2008).How much is a good teacher worth? A report on the motivation and morale of teachers in Ethiopia. London: VSO New York. 